\title{
Bridges E-2 and E-3 in the new railway to the Northwest of Spain
}

\author{
C. Jurado \\ Professor at the Polytechnic University of Madrid, (Spain).
}

\section{ABSTRACT}

During the years 2001 to 2007 it has been constructed in Spain the new railway line of high speed (L. H. S.) that connects Madrid with Valladolid, with a length of 179.6 kilometres. The line Madrid - Valladolid has been put in service to the public on December $23^{\text {rd }} 2007$, and the time estimated to cover the distance is 50 to 55 minutes, which makes an average speed of 215 kilometres per hour, but the railway platform is prepared to reach 350 kilometres per hour. Euros.

The cost of the works has ascended to 264.8 million

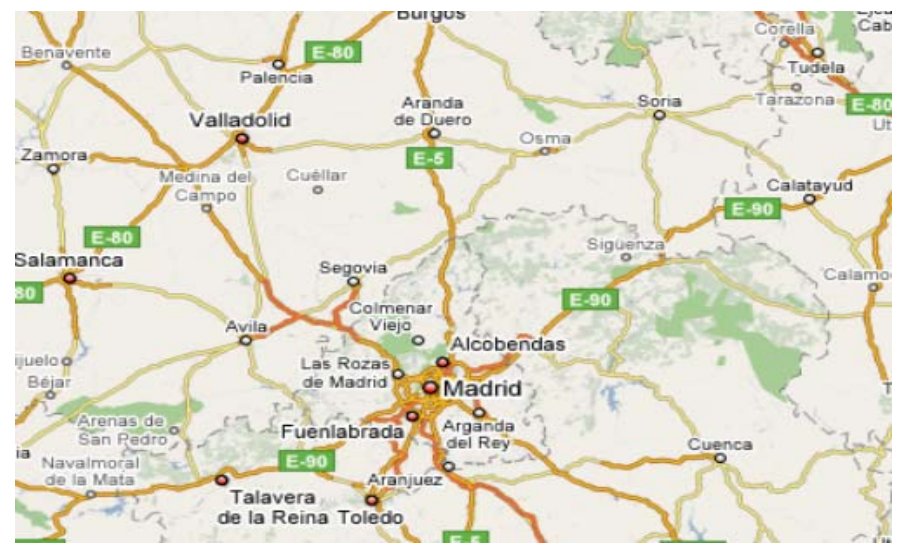

Figure $n^{\circ} 1$ Plan from Madrid to Valladolid

The proximities to Madrid of this new L.H.S., it implies the interference with essential services for the capital such as: roads, railways, big pipes of water supply, etc., and the new necessary structures must be constructed without interrupting the corresponding services.

The first bridge near to Madrid which was necessary to constructed was the structure called in the project E-2.

The project of the bridge $\mathrm{E}-2$ was realized by means of a three-dimensional model of finite elements with the program SAP2000N that includes all the elements of the structure.

The solution consisted in the demolition of the current structure of arch and the construction of a new bridge over the existing railway, fulfilling the requirements of vertical clearance of $7.00 \mathrm{~m}$ and with a span of $22.64 \mathrm{~m}$ needed.

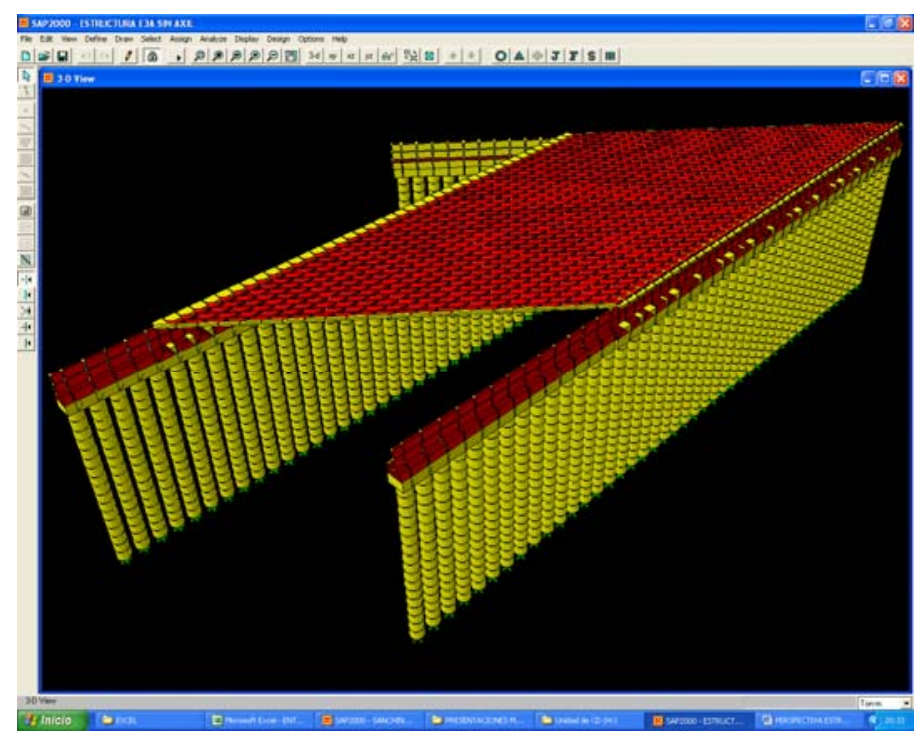

Figure $n^{0} 2$ F.E.M. of bridge E-2 with 1203 nodes, 1098 frame elements and 345 shell elements

The bridge E-3 was divided in two Bridges called E-3 and E-3B. The bridge E-3A has $66 \mathrm{~m}$ of length with a span of $22,70 \mathrm{~m}$. and a vertical clearance of $7 \mathrm{~m}$.

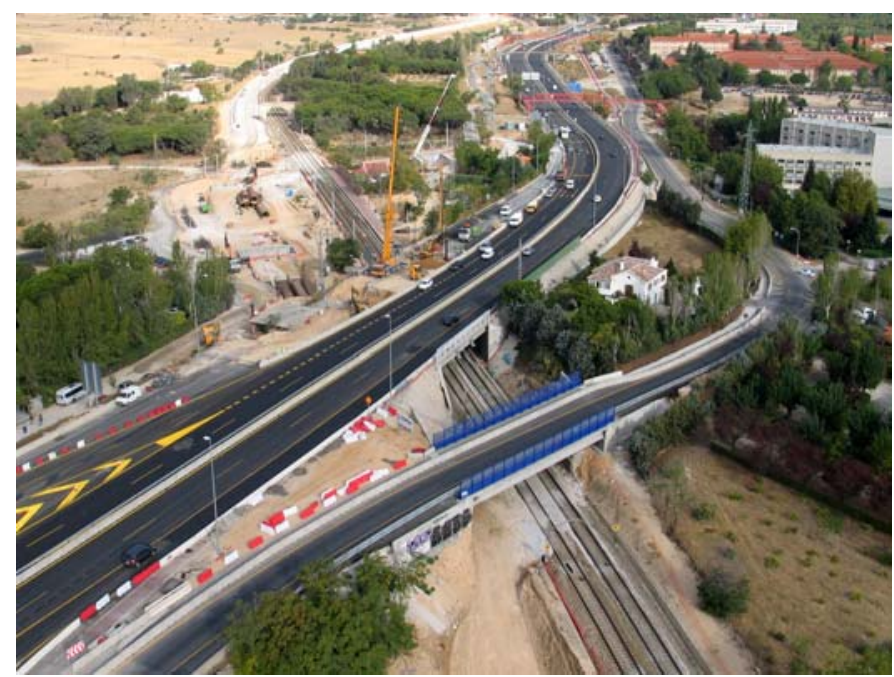

Figure $n^{\circ} 3$ The new bridge E-2 and to the bridge E-3A/3B in construction 